was nutritious, but simple, and her digestion was easy. During the first six months there was no evident change in the symptoms. Afterwards she began gradually and almost imperceptibly to improve, and two years ago felt and looked as well as ever. She, however, did not commence active duties until six or eight months ago, when she began to teach school.

At her visit to ny office, she looked plump and in perfect health. She said, however, that though she had had no cough for two years, she still had a rattling in the left chest on lying down, and some cough on taking cold. If she is tired, she feels it in the chest. Pulse 84. On percussion, the left breast is flatter than the right at apex. Pure tubular respiration of a most dry character at apex, front and back, with great vocal resonance. Obscure crumpling, rather than crackling, below in the breast, but generally the respiration is quite fair, though a shade less soft than at the right.

If the preceding case was not one of tubercular disease, which had proceeded to the degree of sofiening, and probably of excavation or perfect condensation of portions of the lung, I know not how I can ever pretend to recognize any tubercular disease. I believe that it was tubercular, and that it was cured by the thorough use of cod liver oil, \&c. The present condition of the lung is, I presume, much as it will always remain; for it may well be doubted whether a lung affected with such an amount of disease as existed at the first examination, will ever be completely restored to its pristine vesicular structure. It is a case to give us hope, even when there seems to be little or no hope.

The fact incidentally mentioned that the patient could not visit the beach without having hoarseness, is interesting to me, as confirmatory of the view that the lungs of consumptive patients are ir. ritated by a residence near the coast.

\title{
CASE OF OSTEO-ANEURISM.
}

[Communicated for the Boston Medical and Surgica! Journal.]

ThE subject, a young man, first discovered a lameness in the left leg in August, 1854, its immediate seat being referred to the kneejoint, and it gradually increased in severity until walking became impracticable. In January, a solid tumor appeared on the inside of the tibia, near its upper articulation, which was judged to be an ossific deposit simply. The patient continued his avocations until April, when the progress of the disease rendered further labor impossible. At intervals, the tumor would be red, and at such times less painful. In June, the case fell into the hands of a quack, whose irritating applications rapidly developed the character of the disease. Up to this tirne the patient could walk with the assisiance of a cane, but retraction of the leg now became established, and the growth of the sivelling greatly increased. It was intensely painful, and prevented sleep. In August, the case come under my treatment. The 
patient was emaciated, the thigh wasted and the head of the tibia greatly enlarged. The thigh and leg could not be extended beyond right angles. The diameter of the sivelling was four inches, and it was red, hot and painful. A close inspection of it reveuled several other interesting pathological features. 'The outer shell of the bone was elevated in fragments, which were distinctly movable, and in the interspaces there could be felt a powerful pulsation, synchronous wilh the pulsations of the heart. From these observations it was clearly evident that the disease was of the erectile character, developed in the cancellous structure of the bone, and that it was of a very serious nature.

'There appeared to be but a single indication of treatment, and that was, of course, to arrest the supply of blood which nourished the augmented and multiplied vessels; and the only question that could be raised was, whether to accomplish this by the ligature or by compression. I selected the ligature, and applied it to the femoral artery, when the pulsations in the tumor instantaneously ceased, as it was known would be the case, by previous compression of this vessel upon the pubis. Not the least unfavorable result followed; the patient recovered extremely well, the peculiar character of the disease rapidly disappeared, and now, at the expiration of four months, the diameter of the tumor is only three inches, and it is already consolidated. 'The retraction has greatly diminished, and there is every favorable indication that entire recovery will in due time be reached.

Greenfield, Dec., 18555.

\section{OBSERVATIONS ON THE USE OF IRON IN OBSTETRICY.}

by Abrailam livezey, A.M., M.D., LUMbervih.e, PENN.

[Communicated for the Boston Medical and Surgical Journal.]

Is my various sojournings among the medical colleges in Philadelphia I have noticed a diversity of opinion existing among the corps of professors, as to the utility of iron and the advantages obtained by its administration. Of these differences, it will be only necessary, as introductory to my case, to specify two.

Prof. Meigs, as his writings all prove, has unbounded confidence in ferruginous preparations, in all cases where there is atony or flaccidity of the endangium or blond-membrane; in other words, where the blood-globules are deficient, and the watery portion of the blood is in excess, and where tone is necessary to be imparted to the whole system.

Prof. Mitchell, on the contrary, though occasionally a prescriber of iron, at the clinics, through force of custom (he says) rather than from actual confidence in the drug, yet declares it to be his firm conviction that iron is of but litlle value in medicine, and that he is not sensible of ever being able clearly to attribute any marked 